\title{
EDUCAÇÃO E SAÚdE NA PERSPECTIVA DA EXTENSÃO UNIVERSTÁRIA E DA INTERDISCIPLINARIDADE
}

Originais recebidos em: 29/09/2010

Aceito para publicação em: 13/08/2011

Arnildo Korb

Universidade do Estado de Santa Catarina arkorb@yahoo.com.br

Daiane Cristina Teixeira

Universidade do Estado de Santa Catarina daianecristinateixeira@hotmail.com

Daiane Kutszepa

Universidade do Estado de Santa Catarina daianekutszepa@hotmail.com

Renata Mendonça Rodrigues Universidade do Estado de Santa Catarina renamprof@yahoo.com.br

\section{Resumo}

Este artigo relata a experiência da equipe do Projeto de Extensão Universitária "Reduzir a resistência microbiana: um desafio na educação e na saúde", do curso de Enfermagem da Universidade do Estado de Santa Catarina (UDESC), realizado de março a dezembro de 2009 no Município de Modelo/SC. Argumenta-se que uma das possibilidades de enfrentamento do problema da resistência bacteriana aos antibióticos é por intermédio da conscientização da população e da responsabilização das autoridades para a construção de políticas públicas. É por meio da educação que se transforma o pensar e o agir em relação ao ambiente e ao cuidado com a saúde. As ações desenvolvidas na Escola de Educação Básica Dom Helder Câmara, com profissionais de saúde da Unidade Básica de Saúde e profissionais da Secretaria da Agricultura, e nos meios de comunicação demonstraram eficiência, uma vez que promoveram mudanças significativas no comportamento do público alvo no sentido da responsabilidade socioambiental. Demonstraram, também, a possibilidade de articulação do tripé ensino-pesquisaextensão para a produção de novos conhecimentos e para formação de profissionais qualificados para o trabalho com novas visões de gestão e problemas humanos.

Palavras-chave: Resistência bacteriana.

Educação em saúde. Antibiótico.

\section{THE INTERDISCIPLINARITY IN THE UNIVERSITY EXTENSION TO \\ ARTICULATE EDUCATION, HEALTH AND ENVIRONMENT}

\begin{abstract}
This article is about the experience of the group of the Extension University Project 'Reducing the microbial resistance: a challenge in education and health' of the Nursing graduate course at the University of Santa Catarina State from March to December 2009 in Modelo/ Santa Catarina/Brazil. It was discussed that one of the possibilities of associating the bacterial resistance problem to antibiotics by means of the people's conscientisation and authorities' responsibilisation to elaborate public policies. The thinking and doing in relation to the environment and health care is transformed by education. The practices developed at the State School B. Dom Helder Câmara with health
\end{abstract}

\section{(i) (2) Esta obra está licenciada sob uma Licença Creative Commons.}


professionals of the Basic Health Centre, professionals of the Secretariat of Agriculture and some means of communication demonstrated efficience on promoting significant challenges in the considered people's behaviour in terms of socio-environmental responsibility. As a result, it was discovered that is possible to relate teaching-researching-extension in the production of new knowledge and qualified professionals formation to the new management perspectives and human problems.

Keywords: Bacterial resistance. Education in health. Antibiotic.

\section{INTRODUÇÃO}

Entre os maiores desafios na área da educação e da saúde está a articulação de atividades de promoção e prevenção à saúde de maneira intersetorial ou interdisciplinar de modo que se produzam conhecimentos capazes de contribuir para a melhoria das condições de vida da população. O que tem sido feito, na maioria das campanhas educativas, é a mera transmissão de informações que, embora possa contribuir para a resolução de um determinado problema, em pouco contribui para construir estruturas cognitivas nos sujeitos de modo que possam enfrentar outros problemas do cotidiano e, por vezes, similares.

Uma tentativa de relacionar problemas socioambientais e abordá-los de maneira interrelacionada com várias áreas do conhecimento se deu por intermédio do Projeto de Extensão Universitária "Reduzir a resistência microbiana: um desafio na educação e na saúde", executado pela Universidade do Estado de Santa Catarina, em 2009, no município de Modelo, Oeste do Estado de Santa Catarina. A partir de referenciais teóricos que o justificassem - e de maneira democrática —-, e articulação com diversos setores da sociedade, como saúde, educação, agricultura e meios de comunicação, por meio da temática da resistência bacteriana aos antibióticos, buscou-se criar condições para materializar essa perspectiva.

A resistência bacteriana é um fenômeno biológico que garante a adaptação das bactérias aos diferentes ambientes. Essa característica lhes possibilita se multiplicarem na presença de elevadas doses de antibióticos, superiores as terapêuticas. (TORTORA; FUNKE; CASE, 2000). Esse fenômeno se transformou em um problema de saúde pública, e com tendência ao agravamento, caso iniciativas educacionais de fiscalização e orientação aos usuários e profissionais da saúde não sejam encaminhadas urgentemente. O agravamento ocorre pelo uso indiscriminado de antibióticos na automedicação, na venda sem prescrição, na prescrição sem antibiograma, no uso incorreto tanto na dosagem quanto na posologia e nas sobras descartadas no lixo sem tratamento e no ambiente, que provocam a resistência no 
ambiente; ocorre, ainda, por meio de eventuais resíduos encontrados em alimentos de origem animal.

Os antibióticos são utilizados largamente na saúde humana e animal, em virtude dos resultados positivos em tratamentos contra infecções bacterianas e da influência das indústrias farmacêuticas que estimulam a aceitação destes fármacos (NASCIMENTO, 2005).

Na saúde humana, os antibióticos são utilizados para tratamento de doenças e na prevenção de infecções pós-cirúrgicas. Na saúde animal, são utilizados como promotores de crescimento e também no tratamento de doenças. Contudo, para a prescrição correta do antibiótico, seria indispensável a identificação do agente causador da doença. Conforme Nicolini et al. (2008),

Mais de $50 \%$ das prescrições de antimicrobianos se mostram inapropriadas, dois terços [...] são usados sem prescrição médica em muitos países, 50\% dos consumidores compram o medicamento para um dia de tratamento e $90 \%$ compram-no para um período aproximado de três dias.

Outro agravante, conforme pesquisas, é o pouco conhecimento que a população tem em relação à resistência bacteriana, e, devido a esse processo, é crescente o número de mortes por infecções incontroláveis. Somente nos Estados Unidos, em 2006, aproximadamente 19 mil pessoas morreram por infecções incontroláveis.

A inquietação gerada pelo problema levou um grupo de professores do departamento de enfermagem da Universidade do Estado de Santa Catarina (UDESC) a realizar pesquisas em comunidades interioranas objetivando verificar como os usuários do SUS fazem uso dos antibióticos prescritos. Destacam-se algumas das verificações:

Alguns usuários interromperam o tratamento com antibióticos. Entrevistados sobre o destino dessas sobras, $88,2 \%$ responderam que guardaram em casa e $11,8 \%$ descartaram no esgoto ou no lixo. $O$ fato de reter as "sobras" do medicamento no domicílio demonstra outras preocupações que estão relacionadas a utilização numa possível automedicação, a não observância do diagnóstico clínico, a concentração do produto e a validade devido ao armazenamento. Esse é um dos principais fatores que contribui para o desenvolvimento da resistência bactéria. Dos entrevistados e que lançaram as sobras no esgoto, $88 \%$ possuem fossa rudimentar, $4 \%$ possuem fossa séptica e $4 \%$ depositam o esgoto a céu aberto. Os dados indicam a precariedade no sistema de tratamento dos resíduos domiciliares, bem como a falta de responsabilidade. No levantamento dos dados quanto ao nível de conhecimento da população referente ao processo da resistência bacteriana, $76 \%$ dos entrevistados argumentaram não possuir conhecimento sobre o assunto e $24 \%$ alegaram ter alguma informação, mas não conseguiram expressar do que se tratava. Se os desafios apresentados pela pesquisa quanto a desinformação da população sobre as conseqüências do mau uso dos antibióticos e a relação 
com a resistência microbiana podem ser abordados através da educação formal, [...] fica evidente de que existem lacunas na formação geral dos professores de educação básica e superior, assim como na formação dos profissionais da saúde. (KORB; GELLER, 2009)

É neste contexto, do comprometimento da educação, que as ações do projeto de extensão universitária "Reduzir a resistência microbiana: um desafio na educação e na saúde" procuram constituir-se.

\section{MATERIAL E MÉTODOS}

Realizado no período de março a dezembro de 2009, no Município de Modelo, o projeto foi de caráter educativo e informativo. Buscou-se auxiliar no enfrentamento do problema da resistência bacteriana, que é um dos temas abordados na disciplina de microbiologia do curso de enfermagem da UDESC e cujos referenciais foram buscados em pesquisas realizadas nas comunidades do entorno quando se verificou a problemática, especialmente entre usuários do Sistema Único de Saúde e que foram tratados pela antibioticoterapia. Ações também complementaram o Projeto de Extensão "Educação ambiental e saúde: uso de descarte de resíduos de antimicrobianos", realizado em 2008.

A elaboração do projeto foi de caráter participativo, os representantes das instituições opinaram e sugeriram atividades que poderiam ser implementadas. O projeto foi dialético pelo método utilizado, por meio da ação-reflexão-ação. Nas ações realizadas destacaram-se:

- Realização de reuniões com os professores na Escola Dom Helder Câmara. As reuniões ocorriam mensalmente ou com maior frequência, dependendo da reivindicação dos professores quanto à necessidade no apoio às questões de elaboração do projeto geral da escola e na resolução de dúvidas referentes aos conteúdos sobre educação e saúde, e objetivaram orientar os professores na estruturação do Projeto Político Pedagógico da Escola, que a Lei de Diretrizes de Bases da Educação Nacional, Lei $n^{\circ}$ 9394/96, estabelece como sendo um dos processos democráticos que devem orientar a educação escolar. A construção do Projeto "Educação Ambiental e Saúde" pela comunidade escolar teve como proposta pedagógica abordar o tema da promoção da saúde com os alunos por meio da adoção de hábitos saudáveis e com enfoque no uso correto dos antibióticos. As visitas à instituição eram quinzenais. Contatos para orientações de suporte e o fornecimento de materiais ocorriam por 
correio eletrônico. A Gestora e a professora da disciplina de Língua Portuguesa atuavam como mediadores. $\mathrm{Na}$ sala dos professores, encontrava-se um painel contendo a rede de conteúdos referentes ao tema e a serem abordados nas disciplinas.

- No setor da Saúde com enfermeiros, médicos, técnicos em enfermagem, secretário da saúde, agentes comunitários de saúde (ACS), dentista, todos da Unidade Básica de Saúde (UBS), foram realizadas reuniões e palestras sobre o tema da resistência bacteriana, com disponibilização de fôlderes e panfletos para a distribuição aos usuários do SUS.

- Parceria com a Secretaria da Agricultura e a Epagri na realização de palestra, no dia 25 de julho, com presença de autoridades e 250 famílias de pequenos agricultores. A palestra envolveu a equipe do curso de enfermagem, um médico veterinário e um zootecnista do curso de Zootecnia da UDESC. Abordou-se o tema da resistência bacteriana, e explanou-se o uso correto de medicamentos, a adoção de técnicas de manejo no gado bovino que evitem o desenvolvimento de doenças parasitárias e os riscos à saúde humana que os resíduos de antibióticos nos derivados animais podem ocasionar.

- Apresentação do projeto ao legislativo municipal em sessão da Câmara de Vereadores para chamar a atenção da importância da criação de políticas municipais para saneamento urbano e de recursos para o descarte apropriado de eventuais sobras que ocorram nas instituições públicas e privadas no município.

- Imprensa falada e escrita: entrevistas em rádio local e artigos para jornais a fim de esclarecer a comunidade acerca da existência do projeto e de sua intencionalidade, objetivando também desenvolver habilidades orais e escritas nos alunos.

- Participação em eventos científicos para divulgação das ações e estimulo à pesquisa e à escrita dos bolsistas e do público alvo: participação no IX Congresso Nacional de Educação - EDUCERE e III Encontro Sul-brasileiro de Psicopedagogia - ESBPp, no mês de outubro de 2009, na PUC, em Curitiba.

A intenção em atingir todos os segmentos da comunidade teve como objetivo fazer com que as informações chegassem a todos os lares e locais de trabalho, tanto com linguagens diferenciadas quanto em momentos alternados, de modo que a adesão às propostas e as orientações pudessem ocorrer de imediato. 
A metodologia também possibilitou a construção de um percurso de intersetorialidade, que se trata ainda de um dos objetivos a ser buscado no setor da Saúde na maioria dos municípios da federação.

\section{RESULTADOS E ANÁLISE}

Nas atividades de apoio ao projeto de Meio Ambiente e Saúde na E. E. B. Dom Helder Câmara, definiram-se os conteúdos e materiais utilizados na disciplina de Ciências e Geografia, no ensino fundamental, com a construção de um terrário com os alunos para observação das alterações dos ciclos biogeoquímicos e das relações entre os meios abióticos e bióticos. Na disciplina de Matemática, a elaboração de questões problematizadoras e adaptadas ao contexto das turmas auxiliaram a desenvolver competências e habilidades de raciocínio lógico matemático (Anexo I). Na disciplina de História, foram abordadas a descoberta dos antibióticos e as grandes epidemias. Foram exibidos filmes como "A Peste Negra" e outros documentários. Em Biologia, no ensino médio, foram aprofundados os conteúdos de morfofisiologia bacteriana e a relação com a genética, como no caso da transferência de plasmídeo. Tratou-se de conteúdos diferentes daqueles abordados pelos livros didáticos e que estão voltados para concursos públicos, como os vestibulares.

Por influência da equipe de extensionistas, a escola inscreveu-se na Semana Nacional de Ciência e Tecnologia, do Ministério da Educação, realizando teatros, paródias e exposição de maquetes, cartazes e pinturas relacionados à questão da educação e da saúde. Profíssionais da saúde do município, médicos da UBS e um farmacêutico expuseram a problemática do uso dos antibióticos. A equipe de extensionistas apresentou teatros e palestras propiciando discussões acerca do cuidado com a saúde por meio de alimentação saudável e hábitos de higiene adequados, como uma condição para a redução no consumo de antimicrobianos e da resistência bacteriana. A equipe também oportunizou uma palestra com enfermeira especializada em "Parto Humanizado", pois o alto índice de gravidez na adolescência e o despreparo das parturientes que são condicionadas por um sistema de saúde tradicional promovem o parto cesáreo, no qual são utilizados antibióticos.

A participação no IX Congresso Nacional de Educação (EDUCERE) e no V Fórum Ambiental da Alta Paulista, com a apresentação e publicação de artigos referentes às experiências na escola, e com coautoria de professores da escola, revelou a importância de se 
registrar as experiências docentes e demonstrou que, na educação básica, também se produzem conhecimentos valorizáveis cientificamente. Os artigos podem ser acessados em http://www.amigosdanatureza.org.br/index.php?s=noticias\&tipo=1\&a=filtrar\&palavra=arnild o+korb e http://www.pucpr.br/eventos/educere/educere2009/anais/pdf/3268_1517.pdf.

$\mathrm{Na}$ imprensa falada, os alunos da escola realizaram entrevistas e gravaram vinhetas (divulgadas diariamente) sobre a importância do uso correto dos antibióticos. Na imprensa escrita foram publicados os artigos: Superbactérias: as vilãs no ambiente hospitalar; A importância das imunizações para o sistema imunológico; Alimentação Saudável: medida eficaz no controle de infecções; $O$ uso de antibióticos na agricultura e a resistência microbiana; O perigo das visitas hospitalares; A importância do aleitamento materno, entre outros.

No setor da saúde, as reuniões com médicos, enfermeiros, técnicos de enfermagem, agentes comunitários de saúde (ACS), dentista e técnico de saúde bucal, da Equipe de Estratégia de Saúde da Família contribuíram na exposição da problemática da resistência bacteriana e na construção de estratégias de intervenção. Nas reuniões com os agentes comunitários, estes expuseram suas dúvidas e sugestões. Estes atores sociais são fundamentais no processo de promoção e prevenção à saúde, por realizarem visitas às famílias e orientarem quanto à higiene adequada e à importância de uma alimentação saudável, como fatores que previnem infecções. A equipe de extensionistas elaborou panfletos informativos que os ACS entregaram às famílias no momento das visitas, contendo informações relevantes, como a importância dos medicamentos fracionados, quando estes forem adquiridos em farmácias particulares.

Na Unidade Básica de Saúde, no momento da dispensa do medicamento, entregou-se um folder explicativo sobre a resistência bacteriana, acompanhado de explicações pelo farmacêutico acerca da dosagem e da posologia do medicamento. Também foi confeccionado e disponibilizado um banner (Anexo II) sobre essas informações e enviado cópia às demais instituições.

Quanto à palestra com pecuaristas envolvidos na cadeia produtiva leiteira, foi salientado que é preciso respeitar o período de carência dos antibióticos, pois a presença de resíduos em carnes, leite e derivados pode gerar graves reações alérgicas, diarreias, vômitos, riscos nas interações com outros medicamentos, como os anticoncepcionais orais, e a resistência bacteriana. 


\section{CONSIDERAÇÕES FINAIS}

As observações feitas a partir das ações de extensão universitária promovidas pela equipe do Projeto "Reduzir a resistência bacteriana: um desafio na educação e na Saúde" demonstraram a viabilidade e a necessidade de intensificar atividades dessa natureza. $\mathrm{O}$ projeto foi viável, pois articulou o tripé ensino-pesquisa-extensão, demonstrando possibilidades de ressignificação da função social das instituições universitárias, como requer o tratamento dos atuais desafios socioambientais, que envolvem principalmente educação em saúde.

As atividades, ao promoverem o contato dos profissionais da saúde, da educação e da agricultura com as informações, os capacitaram para intervir na realidade. De semelhante modo a equipe de extensionistas passou por frequentes processos de reconstrução de seus conceitos e sistemáticas de replanejamento das ações. Portanto, o processo de ação-reflexãoação, dialético por essência, necessitou de mediações para reelaborar as diversas representações conceituais que se manifestaram durante a execução do projeto, tais como: resistência bacteriana, saúde humana e ambiental, e participação democrática.

À medida que as atividades de controle da resistência bacteriana, implantadas no município de Modelo, envolveram as instituições sociais, possibilitou-se, no setor da saúde, o desenvolvimento da intersetorialidade, que, na atualidade, é a condição para continuarmos pensando a democracia e o controle social lançado a partir do movimento da Reforma Sanitária.

No setor da educação, ao aproximarmos a escola dos demais segmentos, apontou-se uma perspectiva de reforçar a gestão pedagógica e democrática como estabelecida pela Lei de Diretrizes e Bases da Educação Nacional, Lei no 9394/96, que prevê a construção de um currículo escolar que satisfaça a formação geral na perspectiva de alfabetização científica, garantindo condições de formação para a cidadania de modo que possam arriscar-se, quando o dever lhes for atribuído, de propor alternativas para o enfrentamento de problemas do entorno.

O fato é que, na educação, lidamos com a cultura, e transformar traços indesejáveis que comprometem individualmente ou coletivamente os sujeitos requer longos prazos. Além disso, a visualização, ou a mensuração na mudança de comportamento, ainda é um dos grandes entraves na avaliação de projetos socioambientais, pois estão envolvidas variáveis e subjetivações que requerem também longos prazos e metodologias distintas. Nesse sentido, a equipe de extensionistas esteve ciente de que os resultados das ações, devido sua 
complexidade, não poderiam receber, pelo menos nesse momento, um tratamento estatístico para "medir" os seus efeitos. Vigotski (2000) escreveu que a aprendizagem ocorre quando os sujeitos, após assimilados determinados conceitos, os relacionam com o seu cotidiano, atribuindo significados. No caso do uso dos antibióticos como objeto para problematizações no âmbito da prática docente, a internalização das informações ocorrerá quando situações que requeiram o uso desses medicamentos provocarem as reflexões esperadas. Temos, portanto, um elemento significativo e que deve ser considerado em ações de extensão que é o conhecimento de como a aprendizagem se processa nos sujeitos e como esses saberes realizam as transformações no contexto da cultura.

No setor da agricultura, a construção da percepção da inter-relação entre saúde animal e saúde humana é um processo de longo prazo, pois envolve interesses de produção e de mercado, e somente os consumidores que internalizaram conhecimentos acerca dos riscos que podem trazer os fármacos quando usados indevidamente podem cobrar políticas efetivas. $\mathrm{O}$ desafio ainda está em mostrar que, no final da cadeia produtiva, está o ser humano, e é para ele que devem estar inclinadas as políticas de qualidade de vida. As ações no projeto foram um começar no sentido de promover reflexões acerca das inter-relações ecossistêmicas. Mais importante do que controlar microrganismos é incorporar a noção da busca do equilíbrio que biologicamente se estabelece nos conflitos e na destruição dos mais fracos pelos mais fortes, e que a interferência humana, por mais precisa que pareça ser, controla temporariamente e, nos atuais moldes, torna o próprio ser humano vulnerável aos seus atos.

O setor da mídia, considerado por pesquisadores como o quarto poder, por influenciar na cultura, ao estimular o consumo objetivando atender aos interesses particulares, por vezes deixa de avaliar os efeitos que informações presentes em anúncios de produtos de uso agropecuário podem provocar. Pelo fato de os medicamentos de uso humano serem controlados, surge a necessidade de políticas que promovam o uso também controlado de medicamentos no setor agropecuário. Os meios de informação colaboraram, tanto no sentido da disseminação das informações, quanto ao possibilitar que alunos da escola promovam o desenvolvimento de habilidades e competências de linguagem.

Para a equipe de extensionistas, ficou o aprendizado de que saúde pública resulta de um processo de construção coletiva que não se esgota e nem se completa em apenas um projeto. Os desafios se intensificam e se manifestam quando lidamos com questões complexas ou mudamos a nossa percepção sobre os fatos que emergem nessas questões e nos fatos que 
as orientam. A noção de que a educação e a saúde resultam de um processo democrático ficou evidente também para os gestores de instituições, nos quais apostamos na continuidade das ações, assim como no estabelecimento de debates para o enfrentamento de situações que requeiram a responsabilização de todos, por serem esses problemas de natureza política. $\mathrm{O}$ momento requer, também, exemplos que orientem os jovens enquanto "futuras gerações".

O projeto lançou bases para auxiliar outros municípios, contudo não é de pretensão transformar a experiência em receituário, pois é de entendimento da equipe de extensionistas que cada comunidade, por intermédio de suas instituições e dos seus conselhos, precisa debater acerca de seus problemas e buscar alternativas. Se existem na atualidade limitações de conhecimentos específicos que envolvem a questão da resistência bacteriana, se as comunidades apresentam dificuldades em organização política e devido aos interesses particulares que se manifestam, ou se estamos nos precipitando ao antecipar ações, dada a morosidade com que as mudanças ocorrem na sociedade, são questões que suscitam reflexões amplas e complexas sobre as quais as universidades podem e devem se debruçar. Promover ensino articulado com pesquisa e extensão é a condição para a construção da sustentabilidade socioambiental.

\section{REFERÊNCIAS}

KORB A.; GELLER B. M. O conhecimento como fator determinante para o enfrentamento dos problemas ambientais e de saúde. 2009. Disponível em: http://www.pucpr.br/eventos/educere/educere2009/anais/pdf/3029_1500.pdf. Acesso em: 01/05/2010.

NASCIMENTO, M. C. Medicamentos, comunicação e cultura. 2005. Disponível em: http://www.scielo.br/scielo.php?script=sci arttext\&pid=S1413-81232005000500020 Acesso em: 13/04/2009.

NICOLINI, P. et al. Fatores relacionados à prescrição médica de antibióticos em farmácia pública da região oeste da cidade de São Paulo. Ciência e Saúde Coletiva, Rio de Janeiro, v. 13, 2008. Disponível em: http: $</ /$ www.scielo.br/scielo.php?pid=S1413-81232008000700018\&script=sci arttext $>$. Acesso em: 28 fev. 2009.

TORTORA, G. J; FUNKE, B. R; CASE, C. L. Microbiologia. 6 ed. São Paulo: Artmed, 2000 .

VIGOTSKY, L.S. A construção do pensamento e da linguagem. São Paulo: Martins Fontes, 2000. 


\section{ANEXO I- Questões formuladas para a disciplina de Matemática.}

1- A prescrição médica é do antibiótico cloranfenicol $100 \mathrm{mg}$ para tratar paciente com meningite. O frasco na prateleira é de $500 \mathrm{mg} / 5 \mathrm{ml}$. Quantos $\mathrm{ml}$ o paciente deverá tomar?

2- A prescrição médica é de $250 \mathrm{mg}$ injetável do antibiótico benzetacil. Dispomos do medicamento em ampolas de $5 \mathrm{ml}$ com $500 \mathrm{mg}$. Quantos ml deverão ser aplicados no paciente?

3- A prescrição médica é de $20 \mathrm{mg}$ de gentamicina. $O$ frasco contém gentamicina $4 \%$. Sabemos que o frasco é 4\%, ou seja, $4 \mathrm{~g}$ em $100 \mathrm{ml}$. Quantos ml correspondem a $20 \mathrm{mg}$ ?

4- Responda às questões abaixo:

a) A dose prescrita pelo médico é de $50 \mathrm{mg} / \mathrm{kg}$ ao dia, e o paciente pesa $10 \mathrm{~kg}$. Quanto o paciente deverá ingerir de antibiótico por dia?

b) Considerando os dados anteriores, quanto se administraria ao paciente por horário, sabendo que o paciente iria tomar o antibiótico de $6 / 6$ horas?

c) Com os dados anteriores: o frasco do antibiótico de que dispomos contém $500 \mathrm{mg} / 5 \mathrm{ml}$, quantos ml seriam dados por horário (de $6 / 6 \mathrm{~h}$ )?

d) Supondo que o paciente irá tomar o antibiótico por 10 dias, o frasco tem $100 \mathrm{ml}$, e o paciente irá tomar $500 \mathrm{mg}$ por dia, então, em 10 dias tomará quantos mg?

5- A dose prescrita pelo médico para tratar da amigdalite bacteriana é de $50 \mathrm{mg} / \mathrm{kg} / \mathrm{dia}$ de determinado antibiótico a ser dada de 12/12 horas. A criança pesa $20 \mathrm{~kg}$ e o frasco contém $250 \mathrm{mg} / 5 \mathrm{ml}$. Quantos ml serão dados por horário?

6- Foi prescrito o antibiótico amoxicilina $500 \mathrm{mg}$ a cada 6 horas. O tratamento tem duração de 7 dias, e cada comprimidos contém $500 \mathrm{mg}$ do antibiótico. Quantos comprimidos seriam necessários para concluir o tratamento?

7- Um antibiograma demonstrou que um paciente possuía uma infecção intestinal causada por Escherichia coli. Plaqueado o material, e após 24 horas, observou-se que havia 10 colônias por campo. Essas bactérias possuem divisão simples e ocorre em período variável de 15 a 30 minutos. Caso esse material não fosse descartado e fosse mantido em condições adequadas, quantas colônias de bactérias teremos em 24 horas? Calcule com base em 30 minutos e demonstre em um gráfico o crescimento em 2 horas.

8- Devido à resistência bacteriana nos últimos anos, a concentração de princípios ativos aumentou nas cápsulas de antibióticos. A amoxilina, utilizada para o tratamento de amigdalites (infecção nas tonsilas palatinas por Estreptococus), aumentou a sua concentração de $250 \mathrm{mg}$, para $500 \mathrm{mg}$ e agora para 750 e mais o acréscimo de 125 de clavulanato de potássio. Calcule quanto foi o percentual de aumento da concentração do primeiro para o segundo e do primeiro para o terceiro, considerando a inclusão do clavulanato de potássio.

9- Um adulto, de 24 anos de idade, sexo feminino, apresenta calafrios, febre rapidamente crescente $\left(38,5\right.$ a $\left.40,5^{\circ} \mathrm{C}\right)$, dor no "peito" acompanhada de tosse. Este vai ao farmacêutico e ele prescreve amoxifar $500 \mathrm{mg}$ (medicamento similar a amoxicilina, contendo 28 cápsulas) 
para fazer uso durante 7 dias de $8 \mathrm{em} 8$ horas. No terceiro dia após o começo do tratamento, o paciente ainda estava apresentando os sintomas, porém, de forma mais intensa, e resolve ir ao médico. Imediatamente o médico interna o paciente com suspeita de pneumonia, a qual é confirmada pelo exame de laboratório, sendo pneumonia causada por Streptococus pneumoniae. O médico lhe prescreve então penicilina 5.000.000 UI de 6 em 6 horas durante 8 dias, por via intravenosa (injeção na veia), e lhe informa que ele não deveria ter tomado medicamento sem realizar os exames para saber qual foi a bactéria que estava causando a pneumonia, pois isso, além de contribuir para a resistência bacteriana, poderia tê-lo levado à morte. Após ter feito o tratamento corretamente, o paciente melhorou.

a) O que é resistência bacteriana?

b) Qual é a diferença entre um medicamento similar e um medicamento genérico?

c) Quem descobriu o antibiótico e de que forma?

d) Quantas cápsulas de amoxifar deveriam estar em envelope para que, durante 7 dias de tratamento, tomando uma cápsula de $8 \mathrm{em} 8$ horas, não houvesse sobras do medicamento? Neste caso ouve sobra de medicamento? Qual é o malefício para o ambiente e para a saúde das pessoas se as sobras de antibiótico forem descartadas no ambiente?

e) Quantos mg de amoxifar esse paciente tomou?

f) Segundo a regra de nomenclatura científica Streptococus pneumoniae está escrito corretamente? Cite de forma sucinta essas regras.

g) Quantos I de penicilina este paciente ingeriu durante o seu tratamento?

h) Qual é a temperatura do corpo de uma pessoa que não está com febre?

i) Dois meses depois do tratamento, mesmo tomando anticoncepcional esta paciente engravida. Isso tem alguma relação com o uso de antibióticos?

10- Um paciente com 65 anos, imunocomprometido, apresenta falta de ar, tosse e febre acima de $39^{\circ} \mathrm{C}$. Foi à farmácia, comprou antibiótico, e usou por 1 dia. Viu um alerta na televisão sobre a gripe A e resolveu ir ao médico. Chegando lá já não apresentava febre. O médico lhe perguntou se havia tomado algum medicamento (automedicação) e ele afirmou que não. $\mathrm{O}$ médico disse que seus sintomas eram de gripe comum. No dia seguinte a febre reapareceu acompanhada de diarreia e vômitos, obrigando-o a voltar ao consultório. Após realizar o exame de gripe A, cujo resultado foi positivo, ele foi internado. $\mathrm{O}$ paciente foi tratado com tamiflu $75 \mathrm{mg}$ (medicamento fornecido pelo Ministério da Saúde), duas vezes ao dia, durante 5 dias. O médico lhe explicou que o antibiótico pode ter "mascarado" os sintomas da gripe A e que o medicamento era antibacteriano, não produzindo efeitos para a gripe por esta se tratar de um vírus. Responda:

a) O que é sistema imunológico e no que ele contribui para combater a gripe A?

b) O que é uma pessoa imunocomprometida?

c) Supondo que a dose de $150 \mathrm{mg}$ de tamiflu custe $\mathrm{R} \$ 150,00$, quanto de recursos financeiros o Ministério da Saúde deveria dispor para tratar a população de Modelo, SC, que tem aproximadamente 3.930 habitantes? 


\section{ANEXO II - Banner produzido pela equipe extensionistas}

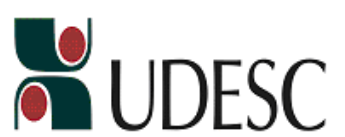

\author{
UNIVERSIDADE DOESTADO DE \\ SANTA CATARINA \\ DEPARTAMENTO DE ENFERMAGEM
}

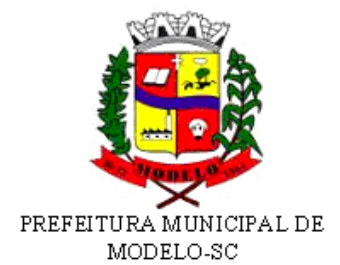

MODELO-SC

UTILIZAR ANTIBIÓTICOS DE MANEIRA INDISCRIMINADAÉ UM PROBLEMA DE TODOS!

VOCÊ SABIA QUE:

- O uso inadequado de antibióticos na saúde humana e animal promove a resistência de bactérias tomando-as "fortes" a açăo do medicamento levando milhares de pessoas a morte por infecçổes incontroláveis.

- No Brasil $50 \%$ dos medicamentos sẵo consumidos sem necessidade. Muitos sem prescriçã̃o.

- As farmácias e drogarias já vendem somente o número de comprimidos prescritos (fracionados).

- As pesquisas para descoberta de novos antibióticos estăo no limite, portanto para não ocorrer mais mortes por infecçỗes incontroláveis, a soluçẫo é utilizar corretamente os antibióticos já existentes.

\section{COMO POSSO CONTRIBUIR:}

- Procurar assistência médica quando apresentar infecçắo e nẵo utilizar antibióticos por conta própria.

- Seguir corretamente as prescriçỗes e orientações médicas e famacêuticas ao realizar tratarnento.

- Tomar os antibióticos nos horários, doses e dias recomendados, sem interromper o tratamento ao sentir-se melhor, assim você evitará sobras do medicamento.

- Adotar hábitos alimentares saudáveis afim de fortalecer o sistema imunológico e evitar infecçổes

- Na agricultura utilizar antibióticos somente quando prescritos pelo médico veterinário e respeitar o período de carência.

- Controlar o surqimento de doenças com a adocấo de medidas preventivas e de hiqiene.
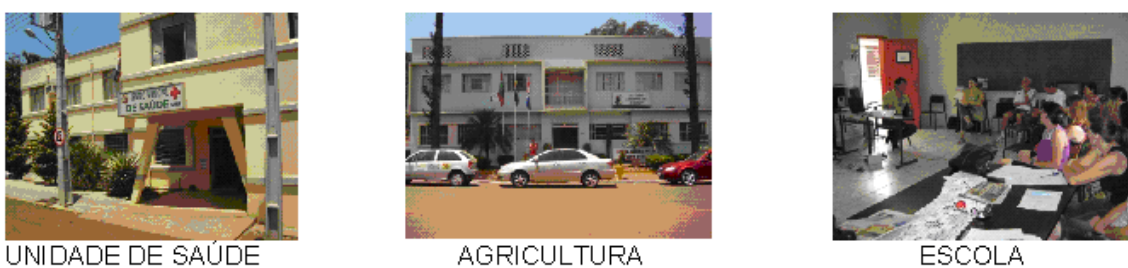